\title{
REARING THE LARV A OF DERMATOBIA HOMINIS LINN., IN MAN
}

\author{
By LAWRENCE H. DUNN \\ Medical Entomologist and Assistant Director, \\ Gorgas Memorial Laboratory, \\ Panama, R. de P.
}

The following article presents some observations on the development of the larvæ of Dermatobia hominis when reared in man, and on the effects of an infestation of these larvæ upon the host. The results of studies on other phases of the interesting life-history and habits of this species of parasitic diptera will be presented in later reports.

In October, 1929, while seated at the edge of a small stream near Summit, Canal Zone, I captured a fly which was hovering about and which had several times alighted on my right knee. This fly proved to be a species of Limnophora, not a blood-sucker, and a number of eggs were found attached to her abdomen. An examination of these showed them to be eggs of Dermatobia hominis. Many of them had developed to the larval stage, the operculum at the hatching end being open and the minute larva inside of each being active and ready to leave its shell when a suitable host was provided.

Through the acquiring of these eggs a good opportunity was afforded for studying the development of the larval stage of $D$. hominis with man as the host, and in view of this it was decided to allow two of the larvæ to enter the skin of my arm.

October 9. At 4 P. M., about six hours after capturing the egg-bearing fly, the glass tube in which it was confined was unstoppered and inverted on the skin of my left forearm. The tube, which was about four inches long and one inch in diameter, allowed room for considerable movement on the part of the fly. The latter was quite active 
and would not rest on the skin except very momentarily, but kept up a continual dashing about in the tube. The larvæ were all protruding from the egg shells, but the swift movements of the fly seemed to prevent them from remaining on the skin for a sufficient length of time to allow them to crawl from the shells. This continued for about five minutes, and it was then noticed, with the aid of a hand lens, that as the fly dashed against the side of the tube one of the larvæ was left hanging to the glass. About one minute later this was repeated and a second larva was left crawling about on the inside of the tube. The fly was then removed and the two small larva inside the tube were picked up on the point of a needle and gently placed on my left forearm at about the upper third of the median flexor region. Since there were no abrasions of the skin at this area, an opportunity was given for observing the entrance of the larvæ into unbroken skin.

The two larvæ were placed in the skin slightly less than an inch apart, and each remained at exactly the site where it was placed. Neither of them could be detected as having moved even a quarter of an inch. They remained so motionless that at first it was feared that they had been injured by the needle in transferring them from the tube to my arm. After watching them closely with a $10 \mathrm{X}$ lens for a few minutes, however, a few faint contractions could be seen, and it was also noted that the anterior, or larger, end of each larva seemed to be sinking very slowly into the skin. This large end of each larva seemed to be about one-third, horizontally, pressed into the skin, and was evidently securing traction through the use of the oral hooks and dermal spines, while the posterior end exerted a progressive forward motion. The larvæ were lying nearly parallel with the skin, and with but a slight arching near the posterior end, so that their position in relation to the skin surface was thus very oblique, and the penetration was at first beneath just the outer part of the skin.

One of the larvæ had practically all of its large anterior part imbedded in the skin in about thirty minutes. It was then able to obtain sufficient purchase with its spines, so that rapid progress was made and the posterior end was soon inside. At the end of 42 minutes from the time this 
larva was placed on my arm it was completely out of sight in the skin and could not be seen even with the aid of a lens. There was absolutely no sensation caused by the entrance of this larva until after the first thirty minutes. Then, as the posterior end was being drawn inside, a sharp pricking, which lasted for about two minutes, was experienced.

The second larva was much slower in effecting an entrance and required an hour and thirty-five minutes to bury itself completely in the skin. At the end of an hour approximately half of the anterior end was inside. At this time I rolled down my shirt sleeve and put on my coat to determine if the rubbing of clothing would loosen the larva or have any apparent effect upon its entrance. After spending about thirty minutes in walking about and in doing some work in the laboratory which necessitated using my arm rather actively, I removed my coat and inspected the larva. At this time it was all buried in the skin with the exception of the tip of the posterior end, and five minutes later that also was inside.

During the night following the entrance of these two larvæ into my skin a marked itching and pricking sensation at the sites of their location was experenced at intervals. Although this did not last more than half a minute at each time it occurred, it was sharp enough to awaken me several times during the night.

October 10. Fourteen hours after the entrance of the larvæ it would have been nearly impossible to locate them. Since I had ringed the sites with ink, however, and thus knew their exact situations, they could with the aid of a lens be detected as pinpoint raised areas which were slightly reddish. After twenty-four hours they were visible to the naked eye as slightly elevated tiny red dots. When viewed closely with the lens the tiny posterior ends of the larvæ could be detected slowing moving up and down in a pumping movement and forcing out minute quantities of fluid.

October 11. This evening a sharp itching was felt at two small pimples which were at first thought to be caused by mosquito bites. One of these was located at the midulnar margin of my right arm, approximately four and a half inches from the wrist joint. The other was on the internal surface of my right thigh about midway between 
the knee and perineum. When these were rubbed there seemed to be more soreness present than usually accompanies mosquito bites. My suspicions becoming aroused, a closer examination was made, and it was then found that each of the small lesions contained a larva of $D$. hominis. A further search showed two more of the larvæ infesting me. One of these was on the flexor side of my

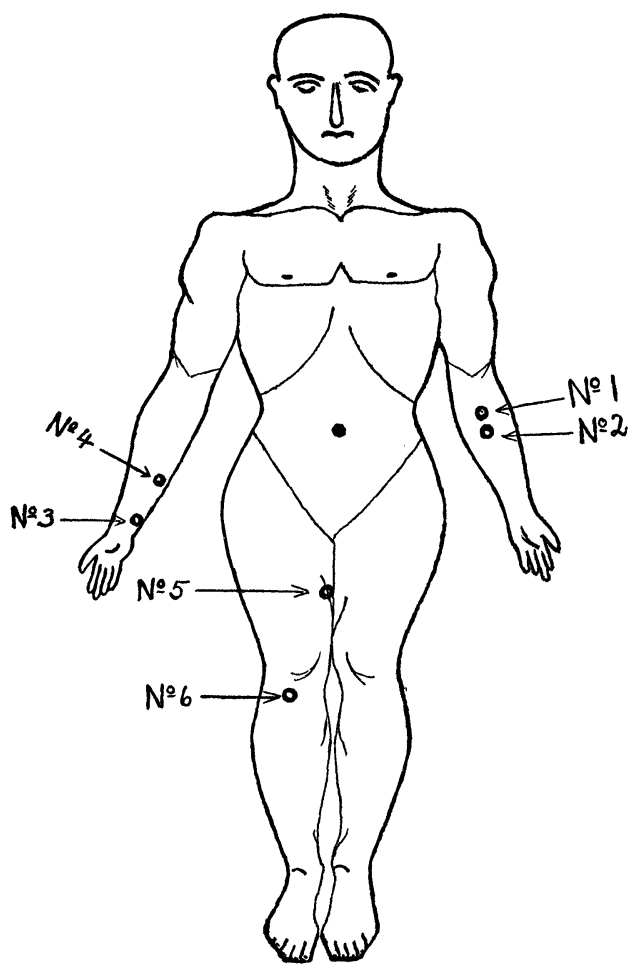

FIG. 1.-Diagram showing locations of the larvæ.

right wrist and the other on my right shin, about two inches below the lower margin of the patella. I had felt nothing which might indicate the presence of these last two larvæ, and it was only the tiny red pimples caused by them that revealed their presence to the naked eye. Apparently it had been just a case of carrying coals to 
Newcastle when I allowed the two larvæ to enter my left arm, since I evidently was already infested with four of them at the time. It is quite certain that these four larvæ were deposited on me by the carrier fly while it was alighting on me just prior to its capture. This placed their entrance into my skin at about six hours earlier than when the two entered my left arm. Finding myself now infested with six of the larvæ I decided to allow them all to remain until they began to produce too great a reaction, either local or general. In order to record observations on the larvæ each one was given a number. The two on the left arm were numbered 1 and 2 ; the one at the right wrist was No. 3, in the right forearm No. 4 , in the upper right leg No. 5, and below the right knee as No. 6. Nos. 1, 2, 4 and 5 were located in areas surrounded by considerable adipose and muscular tissues, while Nos. 3 and 5 were in situations surrounded mainly by fibrous tissue and with much less softer tissues.

October 16. Each lesion, or site of each larva, now appears as a bright red area, about three-eighths of an inch in diameter, and slightly elevated in the center. There is sufficient itching and pricking occurring to cause considerable discomfort. The irritation seems to be much greater during the evenings and nights than throughout the days. No. 6 proves an exception to this, since there is frequently a prolonged stinging or burning sensation experienced when I am walking. While I am at rest this larva seldom causes any annoyance. No. 4 seems to be causing the greatest irritation. This may be due to the location of this lesion on the lower surface of my right forearm, and thus subjected to considerable rubbing on desk and tables while I am at work.

October 1\%. Last night I was awakened by a severe itching and dull burning sensation at No. 4. The burning sensation seemed to feel more like an erosive burn caused by a strong acid than to contact with a hot surface. All the lesions are exuding serous fluid at times. That which comes from Nos. 1 and 4 is slightly tinged with blood.

October 18. Last night the lesions on both arms became very irritating and awakened me several times. There has also been considerable itching and pain today. 
October 20. Yesterday and today there has been but little discomfort. The lesions now have the appearance of small boils. They are a deep red in color, swollen and with some induration of the surrounding area. The indurated area surrounding No. 4 is about an inch and a half in extent.

October 21. A severe stinging pain is occurring at intervals at Nos. 1 and 2 on my left arm. These two lesions are so close together that it is difficult to determine whether it is only one or both that cause the pain. There is also a severe itching at No. 5 and an occasional sharp, stabbing pain in No. 6.

October 22. During the night I was awakened several times by sharp stinging pain in Nos. 1 and 2 . There was intense itching in No. 3 and on two occasions when I awakened during the night I found that apparently I had been scratching this lesion while still asleep. This morning a considerable area of the ulnar surface of my wrist was greatly swollen and an intense itching occurs when the skin is touched, even though it be at some distance from the lesion.

October 24. The lesions have increased in size and have more of the appearance of small boils which have "pointed" and erupted slightly. There is considerable oozing of serous fluid, blood-stained pus and dark-colored matter which I believe is digested blood being defecated by the larvæ. The exudate from the lesions is now sufficient to be quite disagreeable, owing to its staining clothing and bedding, and it is necessary to bandage all the lesions. It is to be regretted that the bandages were not applied earlier, so that the date of possibly a first molt of the larvæ might have been noted. It is my opinion that this molt occurred about October 21, and that the small amount of discomfort present on October 19 and 20 was due to the larvæ being in the first pre-molting period at this time and were not feeding and were quite inactive. Had the bandages been on the lesions at the time it is possible that some traces of the molted skins might have been found which would denote the time of the molt.

October 26 . There seem to be three kinds of local sensations connected with the presence of the larvæ. The first 
of these is an intense itching of the skin of the area surrounding a lesion. This may be due to an infiltration of the tissues with the fæces of the larva and other fluids present in the lesions causing a slight cellulitis. This itching was not constant but occurred at frequent intervals, and is induced by even very slight friction in the vicinity of the lesion. The second sensation is a very irritating pricking which takes place in the lesion. This is probably caused by the rasping of the cutaneous spines or hooks on the larva during any movement of the latter. The third sensation is a sharp, stinging pain, which is believed to be produced by the tearing of the tissues by the oral hooks of the larva when it becomes necessary to use the hooks in order to excite the flow of serum or blood to serve as food.

October 29. Nos. 3 and 6 are now much more swollen than are the other four lesions which are located in areas of more adipose and muscular tissues. The four located in more favorable situations are but little swollen on the outside, but can be felt as hard nodules, each as large as a good-sized marble and seeming to extend into the subcutaneous tissues. During the past three days there has been less of the pricking sensation occurring. This may be due to the lesions becoming walled off so that each larva is to some extent encapsulated. Or, again, it may be due to wearing bandages over the lesions. When the latter were exposed to the air the exudate soon dried and formed small scabs that at times seemed to seal over the small openings of the lesions, and it is quite plausible to believe that in order to burst through these scabs some struggles were required on the part of the larvæ when it was necessary for them to take air or discharge fæcal matter. With the lesions bandaged the exudate is being continually absorbed and the holes left open and moist around the edge. A quite pronounced vesicular eruption has now appeared on both hands and wrists and on my right leg. This is accompanied by an intense itching and a slight oozing of serum from the vesicles.

October 31. During yesterday and today there have been several attacks of excruciating pain experienced from Nos. 3 and 4 . This pain was possibly a nerve irritation caused by the oral hooks of the larvæ tearing the tissues. These 
attacks lasted from one to three minutes each time they occurred. Squeezing the arm just below the lesions seemed to stop the pains to some extent. These two lesions bled sufficiently to stain through the bandages several times today.

November 3. Drops of apparently inchanged blood oozes at intervals from Nos. 1 and 3 when the bandages are removed. Blood-stained serum is exuding from Nos. 2, 4 and 5. No pus is in evidence except a small amount from No. 6. When viewed with a lens at this time each larva may be seen pushing liquid from the hole with a quick, pushing, upward movement somewhat after the action of a plunger of a pump. The downward movement seems to draw back some of the fluid with each jerking back of the posterior end of the larva. When the end of a larva is retracted an occasional air bubble can be noticed coming up through the liquid. There has been very little pain or irritation caused by any of the lesions today.

November 4. A sharp pricking lasting several minutes has occurred at intervals during the day and early evening in No. 6. This lesion and the area surrounding it is quite red, considerably swollen and very sore to the touch. At about seven o'clock this evening when the bandages were removed for a while this larva was found to be pushing out a cast skin. The larva had molted, and since it probably needed more room in the hole for its future growth, was disposing of the cast skin. The movements of the larva caused the skin to emerge in its natural, round, tube-like form. As it came slowly out it formed a tiny crater about $2 \mathrm{~mm}$. high around the hole and then continued to turn back upon itself with the posterior end of the larva pushing up through the center. From the manner in which the molted skin moved slightly from side to side it appeared as though the larva was pushing it up first at one side and then at the other, but keeping it about even so that the rows of hooks of each segment were all out before those of the next segment appeared. After observing the efforts of the larva with a hand lens for about three hours, it was estimated that about one-third of the cast skin was still in the hole. None of the other five lesions have caused very much discomfort. 
November 5 . This morning the molted skin from No. 6 was found all outside of, and still surrounding, the hole. This larva was quite active and caused considerable irritation during the day. None of the other five lesions caused much discomfort. The fluid is exuding in a smaller amount than usual, and it seems to be comparatively clear serum with the exception of that which is coming from Nos. 1 and 5, which is rather heavily tinged with blood. The other five larvæ are probably also preparing to molt.

November 6 . The larva in No. 3 molted and ejected the cast skin during the A. M. Following the ejection of the skin, which was found adhering to the bandage, this lesion exuded a considerable amount of blood during the day. Frequent sharp, stinging pains at No. 6. This pain is so severe that at each attack it is necessary to remove the bandage and place a hand on each side of the lesion and press upward in order to stop the action of the larva. There is only a small amount of deep tissue surrounding this lesion and the larva is situated parallel with the surface of the skin.

November 8. Cast larval skins were ejected from Nos. 1,2 and 4 this P. M. This leaves all the larvæ molted except No. 5. Both arms are now very sore, and sufficient bloom and serum is exuding from the lesions to stain through the bandages soon after they are applied.

November 10 . No. 6 has caused excruciating pain at intervals throughout the day. During the evening one attack lasted for fifteen minutes and became almost unbearable. Pressing on the sides of the lesion and allowing cold water to run on it seemed to have but little palliative effect. This attack was followed by bleeding. Blood oozed from the lesion in a thin stream and continued until it had soaked three gauze pads that were applied one after the other. No. 1 also bled sufficiently at one time this evening to stain through the gauze pad, bandage, shirt sleeve and coat sleeve. During the night I awakened to find that this lesion was again bleeding and to the extent of soaking through the dressings and sleeve of my pajamas.

November 11 . No. 1 gave the most trouble today. During the afternoon it suddenly developed a severe, deepseated pain which seemed to extend for some distance up 
and down my arm. After this pain had lasted for about a minute, bleeding began. From the way in which the blood bubbled from the lesion it appeared as though it came from a small artery. This continued for several minutes until by applying cold compresses to the lesion it was induced to stop.

November 12. The exudate from No. 3 today consists largely of pus with a very fetid odor. Serum mixed with dark-colored digested blood and pus is oozing from No. 4. Several spasms of pain occurred during last night and today in No. 5. This pain was severe enough to awaken me several times during the night. No. 1 again bled profusely on two occasions today. The bleeding started both times soon after the bandage had been removed. The blood welled out in a small stream, and it was necessary to hold my arm beneath running tap water for some time before it ceased. These hemorrhages were sufficiently severe to cause me to consider the advisability of having No. 1 removed in order to prevent the possibility of losing a considerable amount of blood during the night while asleep. I have decided, however, to delay any action and await developments for another day or so. Both times that the bleeding occurred from this lesion it was preceded by a sharp, deep-seated pain which was sufficiently acute to cause a slight nausea.

November 13. The sharp pain and bleeding from No. 1 again occurred this afternoon just after a fresh bandage had been applied. Blood-stained serum is exuding from Nos. 2 and 5. Serum mixed with blood and pus is issuing from No. 5, while pus only is being discharged from No. 3 . A cast larval skin was expelled from No. 5 today. All the larvæ have now molted with nine days' difference between the time the molted skin was ejected from No. 6 and No. 5 . Both arms are now very sore and a lymphangitis extending almost from the elbow to the axilla of my left arm is evident. The epitrochlear and axillary lymph nodes of the left arm are enlarged to about the size of marbles and are tender to the touch. The nodes of the right arm are also swollen and tender, but not to the same extent as on the left side. A general feeling of lassitude which is quite marked has been experienced during the past few days. 
This may be due to absorption of toxins from the lesions and may also be influenced by the many times that I am awakened each night by the larvæ. The lesions are now emitting a fetid odor which becomes very disagreeable if the bandages are not changed frequently. When they remain unchanged during the night the odor is extremely offensive in the morning.

November 14. During the night I was awakened by a severe pain in No. 3 and a contraction of the muscles of the wrist and forearm. This served to draw my hand back on the wrist, and I was unable to straighten the hand except by using my left hand. It was necessary to place the hand and wrist in cold water before relief was afforded. Considerable blood and serum oozed from this lesion following the pain and contraction. During the past few days this lesion has become much swollen and is very red and inflamed. The center of the lesion is taking on a dark purple appearance, although the aperture is well down on one side near the base of the swelling.

November 1\%. No. 5 is very painful and the muscles of the leg are stiff and sore to the touch, and is causing some lameness. All the lesions are oozing considerable serum and pus. I seemed to be quite feverish at one time when I awakened last night, but the feeling of lassitude was so great that no temperature was taken.

November 19 . No. 3 has been causing severe pain and muscular contraction at intervals during the past four days and the wrist is very painful. No. 6 has been quite sore for several days, and this evening it was found that another opening had developed in it. This new opening is located on the side opposite the original opening and about where the anterior end of the larva seems to be. It is a question whether this second aperture is due to action of the oral hooks of the larva or to sloughing caused by pus inside the lesion.

November 20 . No. 3 awakened me several times during the night by piercing and nauseating pain. This morning it was found that there were two more openings in this lesion and with serum and pus oozing from each. One of these openings is near the center of the lesion and the other at about where the anterior end of the larva is situated. 
The development of this opening in the center of the lesion is evidence that these extra openings are due to ulceration.

November 21. Serum and pus with a very disagreeable odor is exuding from all the lesions at this time. At No. 3 the anal end of the larva is visible in the opening and the stigmal plates may be seen. The larva in No. 6 has been protruding from the opening about a quarter of an inch all day, regardless of whether the bandage is on or not. When the bandage and gauze are in place the protruding end of the larva makes a sort of a small burrow in the gauze pad. Several times during the day the larva twisted about rather vigorously as though it might be about to emerge.

November 22. The larva in No. 6 still remains with its posterior end protruding from the hole the greater part of the time. The pain from this lesion becomes so intense at times that it is almost impossible to walk until the paroxysm is over. These pains (although of frequent occurrence) are, fortunately, of short duration. Blood and serum issues from the new opening after each of these attacks. The larva in No. 3 seems to be enlarging the opening in the lesion today.

November 23. Larva No. 6 is still twisting about quite frequently and causing considerable pain. It continues to have its posterior end outside the hole and burrowed into the dressing during the greater part of the time. The dressings are very loose and would not prevent the larva from emerging. The dressings are removed frequently but the larva makes no attempt to come out any further when they are off. With the exceptions of Nos. 5 and 6 all the larvæ seem to be enlarging the apertures to the lesions. There is considerable discharge of serum, digested blood and pus from No. 5 today. The feeling of lassitude still continues and short spells of slight fever seem to occur at intervals. I am still being awakened many times during the night by the larvæ.

November 24. The posterior end of the larva in No. 2 protruded from the hole about a quarter of an inch this morning. When viewed with a lens the larva could be seen enlarging the hole by means of a rasping movement of the spines on its posterior end. The hole is now about 
$5 \mathrm{~mm}$. in diameter. The larva looks larger and has a yellowish color. The larva in No. 1 has a reddish tint as though it is still taking blood as food. No. 6 is still protruding the greater part of the time and continues to be very painful. There is considerable discharge from No. 5 and much irritation present.

November 25. Larvæ Nos. 2 and 4 spent considerable time last night in enlarging the openings to the lesions occupied by them and they both emerged this morning. While in the bath taking a shower I noticed larva No. 2 as it came straight up out of the hole and dropped over on my arm. I immediately placed this larva in a test tube, and was about to return to the shower when I saw that No. 4 was protruding from the opening with a slight side to side weaving motion. It slowly and easily continued its emergence until it finally came entirely out with almost a slight spring. There was absolutely no pain or sensation as these two larvæ emerged, and had I not happened to see them as they did come out I should not have known that they were emerging. From the time when larva No. 1 began to enter my arm as a tiny larva until it emerged mature and ready to pupate was 46 days and 15 hours, while the period of infestation with No. 4 was approximately 46 days and 21 hours. These two larvæ emerged within ten minutes of one another. This is probably the first record of the exact time between entrance and emel:gence of a larva of Dermatobia hominis. This afternoon a sharp, stinging pain and much movement was felt in No. 6. The bandage was removed and the larva was found to be protruding somewhat more than it had been previously. During several minutes of observation the larva did not appear to be making any efforts to come out fruther and the bandage was replaced. About fifteen minutes later a movement was felt between the dressing and my skin, and an examination showed that the larva had emerged and after crawling nearly to the edge of the gauze pad was burrowing into the latter. There was no sensation felt with the actual emergence of this larva and it was only the movement of it against my skin that apprised me of the emergence. See Plate 13. 
November 26. No. 3 gave numerous twinges of pain during the day and pus continued to ooze at times from the two extra openings in this lesion. There has been very little movement felt at Nos. 1 and 5 today. This evening the bandages were left off for a time and the larvæ were observed with a lens. Both these larvæ could be seen working vigorously enlarging the apertures to the lesions. This was done entirely by the spines on the posterior segments. They were rubbed against the side of the hole with a rasping motion, and this was carried on at first one side of the hole and then the other. It reminded one of enlarging a round hole with a round file. At intervals of from five to ten minutes each of the larvæ protruded from its hole for more than a quarter of an inch as though testing the diameter of the opening to see if it be large enough to permit the emergence of the larger anterior end. After protruding for a few minutes the larva withdrew within the lesion and again began its rasping on the edge of the opening. This continued for about three hours, when the bandages were again applied. There was considerable movement in No. 5 today and the escape of pus and digested blood from this lesion was sufficient to soak through the dressing twice during the day.

November 2\%. Larvæ Nos. 1 and 3 were quiet and gave very little trouble during the night, but this morning they became active and protruded so far that it was thought that they were about to emerge. No. 3 continued more or less movement during the early morning and the dressing was removed several times to see what was taking place. At each time the larva was partly out of the hole, but it always withdrew again after coming out about so far. At 10 A. M. a movement was felt on my skin at the lesion and upon examination the larva was found to be coming out. It appeared to be doing very little struggling, yet it slowly came from the hole and dropped over on my arm.

November 28. Larva No. 1 seems to be dividing its time between protruding for about half an inch and working very industriously at enlarging the hole, although the latter is now fully $5 \mathrm{~mm}$. in diameter.

November 29. While I was taking a shower this morning, larva No. 1 protruded for nearly half an inch for a 
few moments, when it again withdrew. Ten minutes later it again began to come out, and this time continued very slowly and steadily to emerge. The emergence covered a period of about one-half hour. The exact infestation period of this larva was 50 days and 151/2 hours.

December 3. The last larva, No. 5, has been alternating between enlarging the hole of the lesion and protruding its posterior end during the past four days, until it emerged some time between $12: 30$ and 6 o'clock this morning. It emerged and crawled outside the bandage without awakening me, and was found in the bed at $6 \mathrm{~A}$. M. It was rather surprising to find that this larva was the smallest of the six. It was expected that since it had been located in an area with an abundance of muscular and adipose tissues together with its longer period in situ, about $543 / 4$ days, that it would be the largest.

A slight exudate continued from the lesions until from three to five days following the emergence of the larvæ. Then as the discharge ceased and the swelling subsided the apertures soon healed.

With the exception of No. 6 the scars left by the lesions were very slight ones. Eight months later well-colored purple and brown spots still mark the sites of the two openings of No. 6.

The size and weight, taken within two hours after emergence of each of the larvæ were as follows:

\begin{tabular}{|c|c|c|c|c|}
\hline Larv & No. & Length & Diameter & Weight \\
\hline 1 & .......... & $22 \mathrm{~mm}$ & $10 \mathrm{~mm}$. & 0.692 gram. \\
\hline 2 & .......... & $20 \mathrm{~mm}$. & $9 \mathrm{~mm}$. & 0.575 gram. \\
\hline 3 & 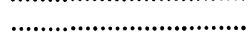 & $25 \mathrm{~mm}$. & $11 \mathrm{~mm}$. & 0.725 gram. \\
\hline 4 & 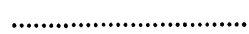 & $24 \mathrm{~mm}$. & $11 \mathrm{~mm}$. & 0.740 gram. \\
\hline $\mathbf{5}$ & 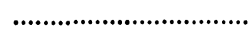 & $20 \mathrm{~mm}$. & $7 \mathrm{~mm}$. & 0.480 gram. \\
\hline 6 & 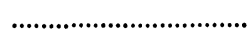 & $20 \mathrm{~mm}$. & $8 \mathrm{~mm}$. & 0.520 gram. \\
\hline
\end{tabular}

Soon after each larva emerged it was placed in damp sand and sawdust to pupate. The pupation periods were from twenty-two to twenty-four days, at the end of which time the adult flies emerged. 
Psyche, 1930 Vol. 37, Plate 13.

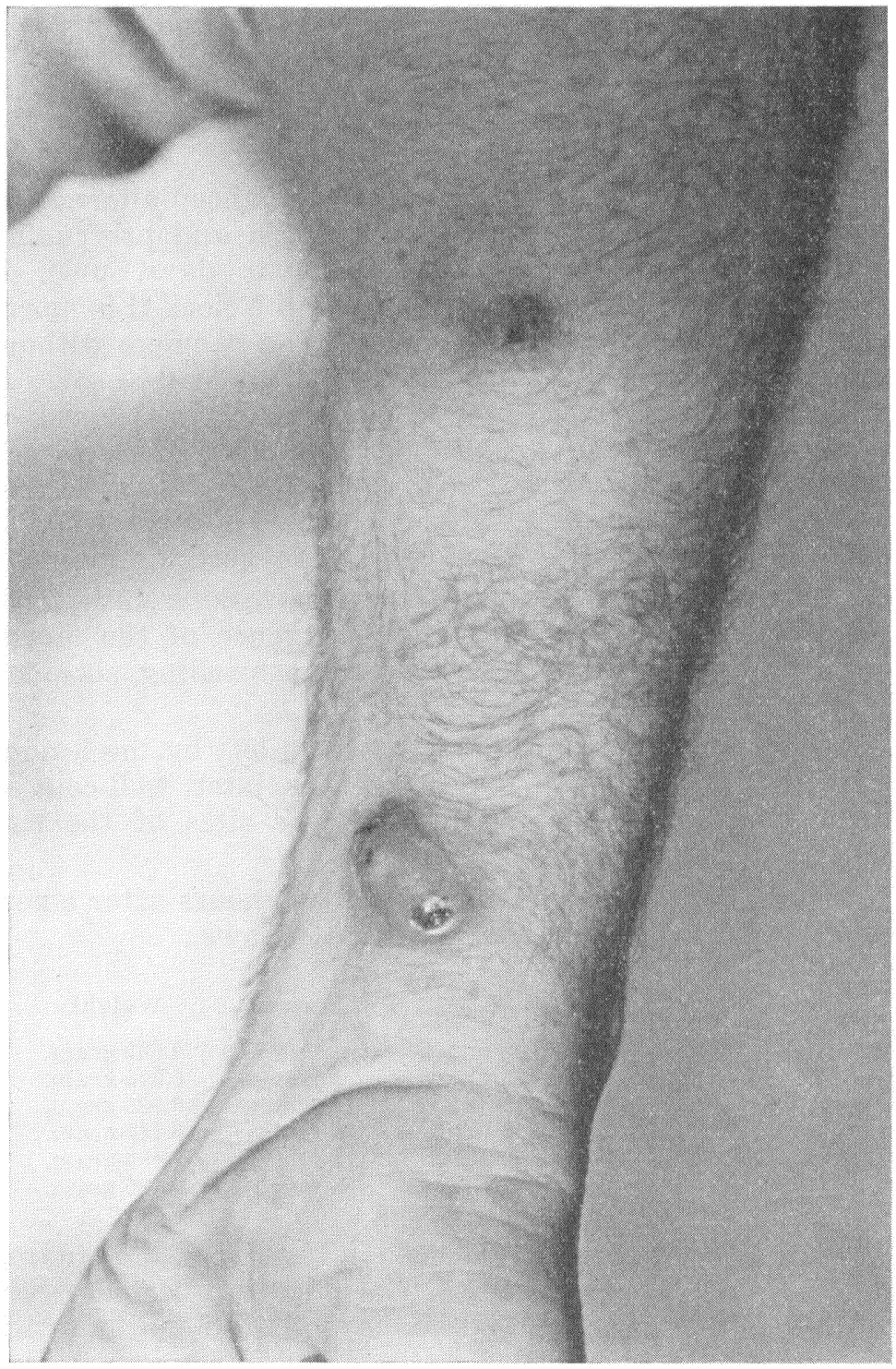

Dermatobia hominis

Explanation of Plate 13.

Appearance of lesion No. 3 (at wrist) two days before the larva emerged, and of No. 4 eight hours after the larva emerged. 

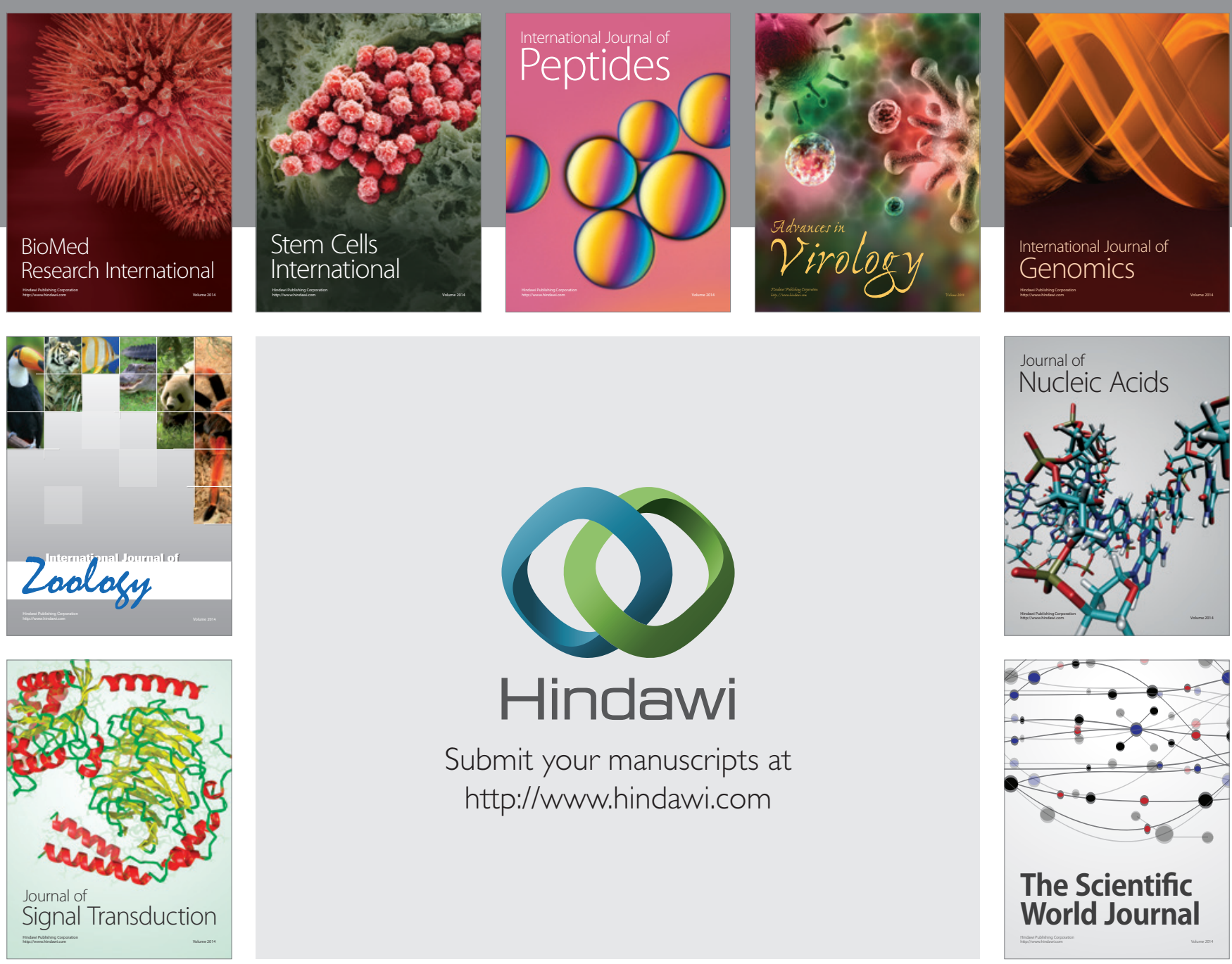

Submit your manuscripts at

http://www.hindawi.com
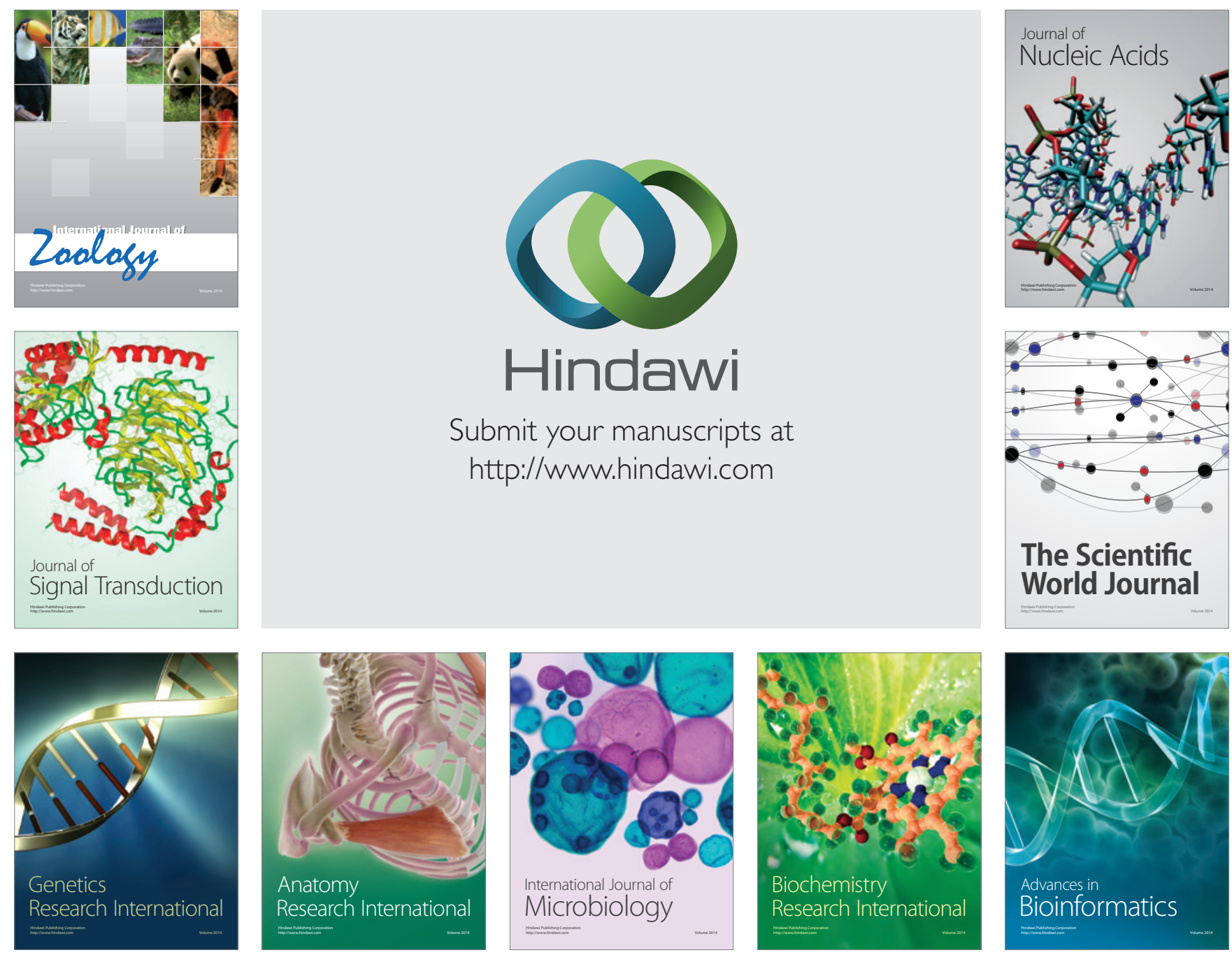

The Scientific World Journal
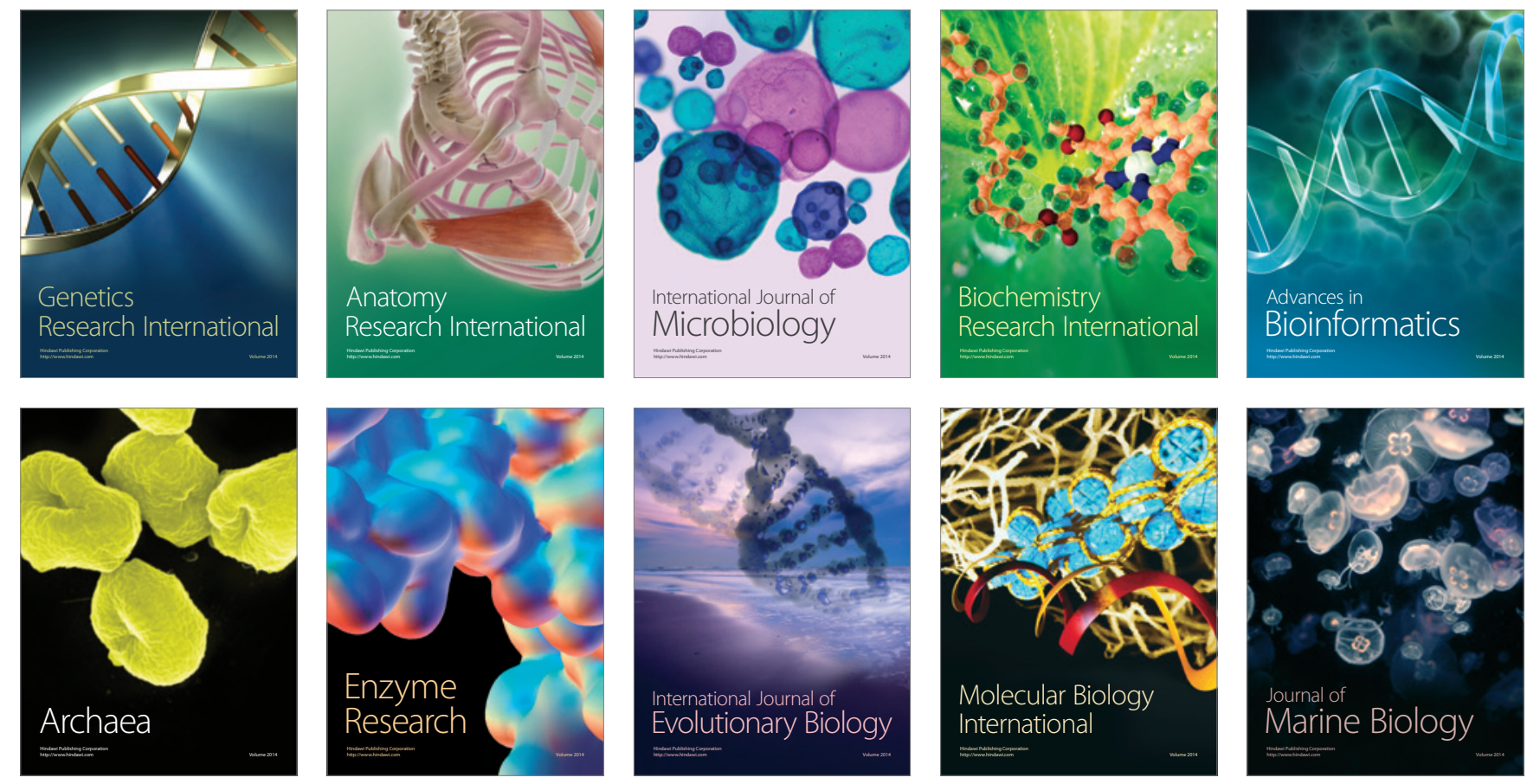